\title{
Feasibility Evaluation of Integrating Usability Engineering Issues in a Design for Multi-X Collaborative Framework
}

\author{
Stefano Filippi \\ DIEGM Department, University of Udine, Udine, Italy \\ E-mail:filippi@uniud.it \\ Received December 18, 2010; revised January 4, 2011; accepted January 9, 2011
}

\begin{abstract}
Design for manufacturing, design for assembly, and, in general, design for $\mathrm{X}$, are methods helping an effective generation of industrial products. In parallel with the development of these methods, the research about usability engineering has generated many important results, both from the design, and the evaluation and testing points of view. The research described in this paper aims at evaluating the feasibility of the integration of two new usability methods, the design for innovative usability - DFIU -, and the integrated method for usability evaluation and testing - IMUET -, in an existing design for X named design guidelines collaborative framework - DGLs-CF -. Indeed, the DGLs-CF is a design for multi-X method, given that it covers both the manufacturing and the verification phases of the industrial product lifecycle. All these methods are currently under development by the author's research group. To evaluate this feasibility, the first task of the research aims at describing and classifying the components of the three methods. Next, these components are semantically related to each other. Finally, the last activity verifies the compatibility between the components of the two usability methods and the data structures of the DGLs-CF to check the feasibility from the implementation point of view. The result of this research will consist of precise indications both for the development of a design for multi-X collaborative framework covering homogeneously the design, manufacturing, verification, and use phases of the industrial product lifecycle, and to be used as a reference for researchers interested in considering the integration of usability issues in their design tools, methods, and processes.
\end{abstract}

Keywords: Design for Multi-X, Usability Design, Usability Evaluation and Testing, Product Lifecycle, Design Guidelines

\section{Introduction}

The first method for the usability evaluation and testing of industrial products appeared in the research landscape in the ' 80 s, while some attempts to offer a real help to the industrial designers and engineers in generating usable products took place in the '90s [1]. Meanwhile, and unfortunately in parallel, with very few contact points, all the phases of the industrial product lifecycle have been analyzed, related to each other [2-5] and many design for X - DfX - methods have been developed and applied successfully in the field [6,7] For example, design for manufacturing - DfM - actually helps in designing industrial products for their optimum generation with the available technologies, or design for assembly - DfA
- suggests effective guidelines to design industrial products for the best assembly procedures [5]. Hybrid methods exist as well, named design for multi-X; they cover more than one phase of the lifecycle [8-10].

Even the usability field has kept evolving since the ' 80 s, by developing always new methods both to generate guidelines to design the usability inside the industrial products and to evaluate and test these products from the usability point of view. Modern approaches to usability design exploit analogies and metaphors; moreover, they start to share with other research fields some logical methods for product innovation, as the theory of inventive problem solving - TRIZ -, or the axiomatic design [11-13]. Regarding the usability evaluation and testing, now the methods are based on hybrid interpretations of 
the classic pluralistic walkthrough, co-discovery learning, etc., integrated by the modern technological solutions for data capturing and processing.

The goal of the research described in this paper consists in trying to eliminate the gap between the DfXs commonly used in the industrial design and engineering domains and the usability methods, by merging them homogeneously in a collaborative framework. The starting point is the design guidelines collaborative framework - DGLs-CF -, a design for multi-X method for product design and process reconfiguration, covering the design, manufacturing, and verification phases of the industrial product lifecycle, and developed in the last years by the author's research group. The DGLs-CF presents a well organized knowledge structure and some modules for information processing. These are the best conditions to organize the pieces of information regarding the usability engineering, in order to map and integrate them in the DGLs-CF. This could result in some modifications of the DGLs-CF itself, but this is normal and well accepted, because the tuning/update of the DGLs-CF will be in any case a valuable enhancement. In other words, the goal of the research is to enlarge the coverage of the DGLs-CF by integrating it with a state-of-the-art design for usability component.

\section{Materials and Methods}

Figure 1 summarizes the context where this research takes place and highlights all the components involved. The $\mathrm{x}$-axis contains some phases of the industrial product lifecycle, while the $y$-axis represents the development of DfX and design for multi-X methods related to these phases. Also these methods are ordered by time. In fact, at the beginning, the design guidelines - DGLs - was a method that simply suggested some actions to be performed to the product model to get it compatible with the available manufacturing technologies. The DGLs became DGLs-CF when the issues related to the geometrical verification of the physical representation of the product were added to the framework. In the last year, two new components have been developed: the integrated method for usability evaluation and testing - IMUET - and the design for innovative usability - DFIU -, covering respectively the evaluation and testing of the industrial product usability after the production phase, and the embedding of usability issues inside the product since the design phase. As highlighted in Figure 1, all these methods, except for the IMUET, cover the design phase (the grayed areas represent this coverage); in fact, this is exactly the role of the DfXs, to influence the product design by looking forward at the next phases of the product lifecycle. The biggest rectangle in Figure 1 represents the goal of the research, the design for multi-X named DGLs-CF*, an integration between methods coming from the industrial design and engineering and the usability fields.

The elements shown in Figure 1 are described in the

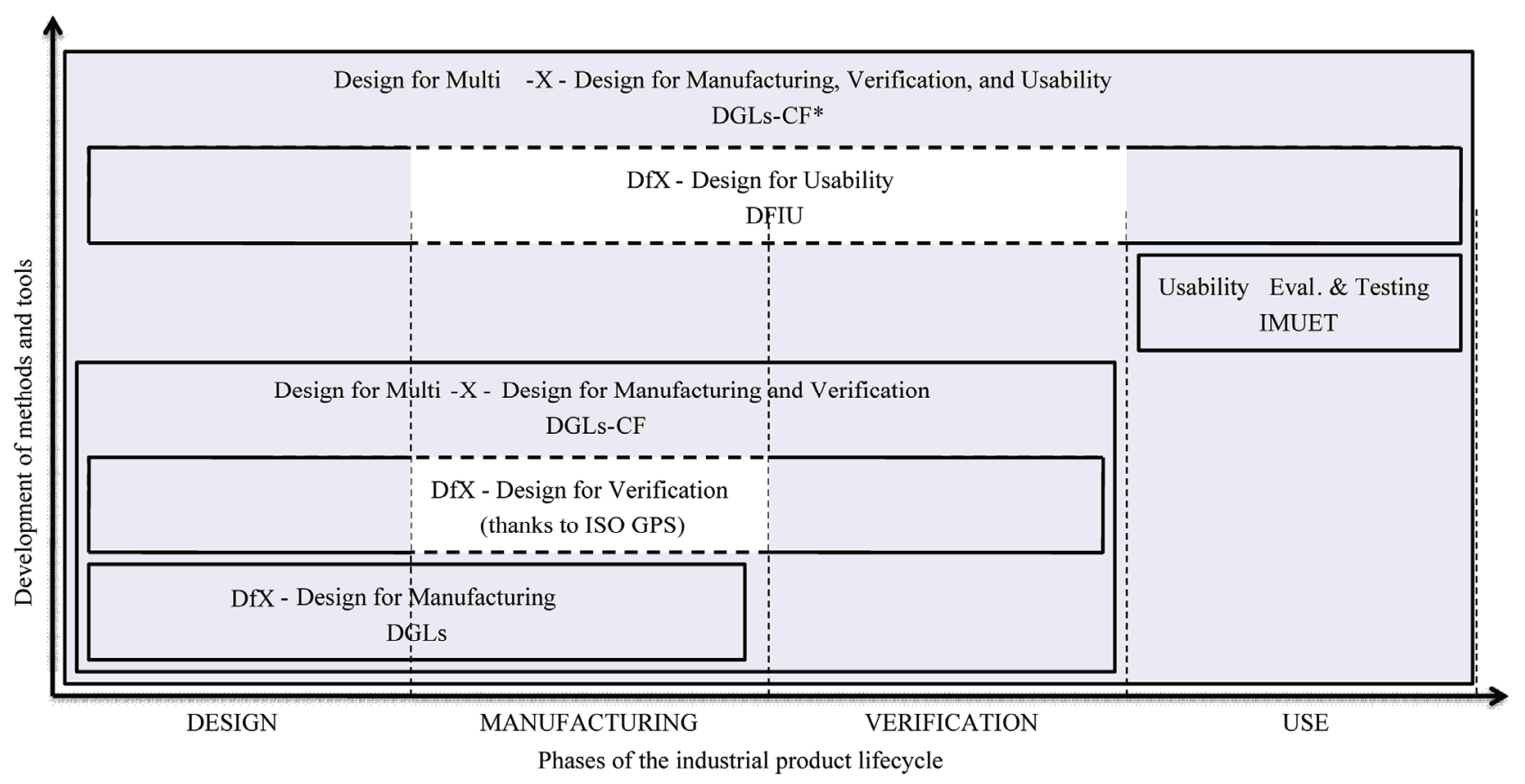

Figure 1. The methods involved in this research, mapped on the phases of the industrial product lifecycle (x-axis) and ordered by their development time (y-axis). 
following. The descriptions are quite short because the classification of their components is the topic of the first task of this research, together with the analysis of the relationships and interactions among these components.

\subsection{The DGLs-CF}

The author's research group has been developing the DGLs-CF during the last five years. The DGLs-CF is an articulated knowledge based framework used to structure, manage, and generate many pieces of information related to the industrial product during the design process [14-17]. The DGLs-CF is an evolution of the previous DGLs and it was obtained by adding the concerns about the verification of the physical product. This enhancement happened thanks to the adoption of the ISO geometrical product specification - GPS - [15]; for this reason it must be pointed out that in the DGLs-CF the scope of the verification is limited to geometrical issues.

Figure 2 shows the main level (A-0 level) of the IDEF0 diagram used to describe the DGLs-CF adoption, named DGLs-CF roadmap. This diagram is valuable because it shows all the interface components between the DGLs-CF and its application domain.

Starting from collecting the information about the application domain, expressed in terms of product features and manufacturing/verification process characteristics, the DGLs-CF generates some redesign/reconfiguration packages; these are guidelines to maximize the compatibility between the product and the available technologies to manufacture and verify it.

The DGLs-CF is really valuable here because its precise data structures, rational information flows, and clear procedures, make it the best way to collect, classify, and put into relationship all the knowledge involved in the present research.

\subsection{The Design for Innovative Usability - DFIU}

The design for innovative usability - DFIU - is a DfX method to generate usability design guidelines related to specific industrial products. Its development started one

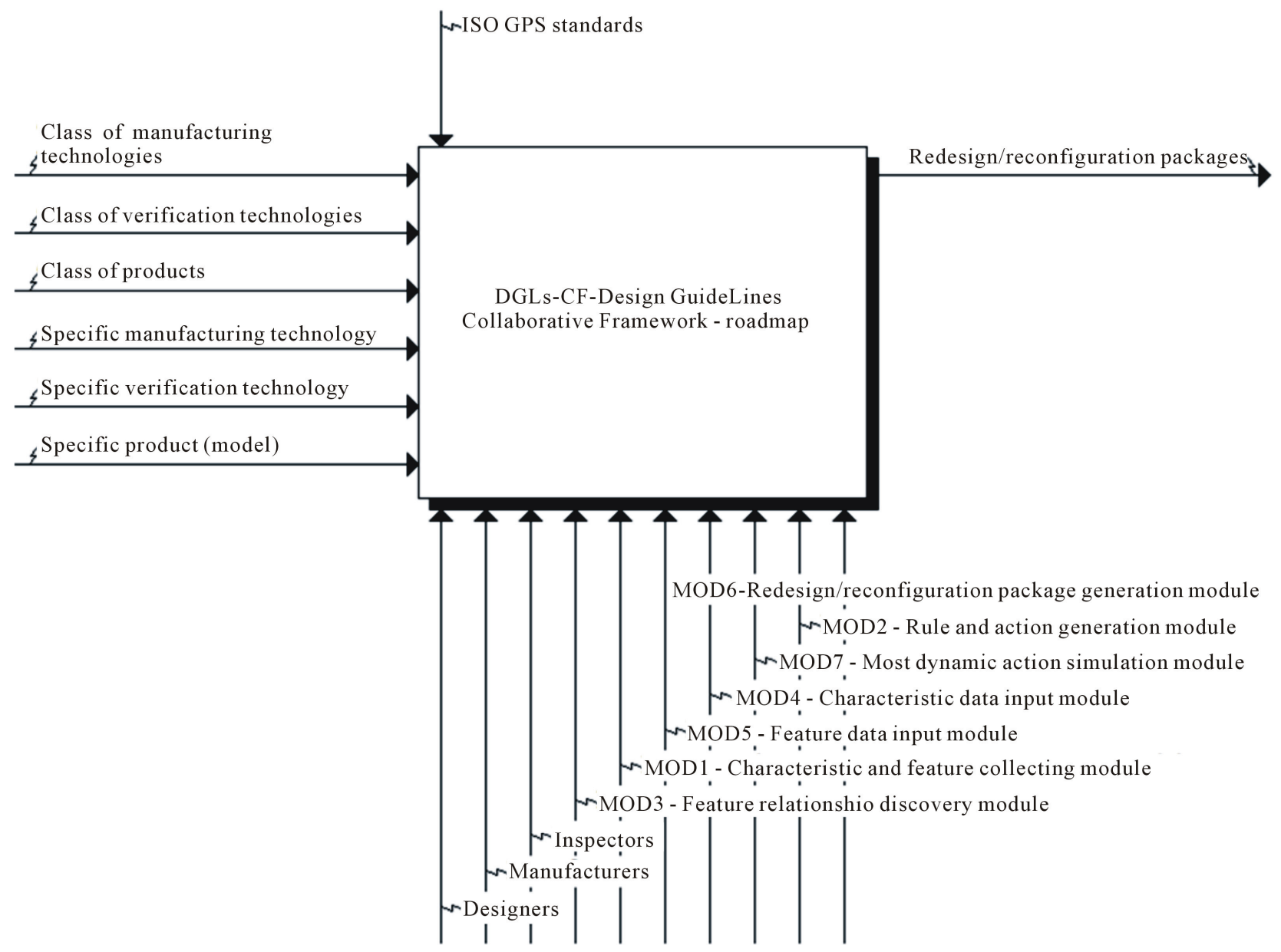

Figure 2. The main level (A-0 level) of the IDEF0 diagram describing the DGLs-CF adoption. 
year ago and, even if the application in the field has been quite limited up to now, the results appear interesting and very promising for the next steps.

Starting from the application domain - the context where the product is developed - and from the description of the final users of the product, the DFIU generates the result expressed as a set of guidelines, helping the users in designing the usability inside the product.

The most interesting aspects of the DFIU are the highlight of the contact points between usability issues and the state-of-the-art methods currently used for the industrial innovation [11-13], and the exploitation of these methods in generating the usability design guidelines.

\subsection{The Integrated Method for Usability Evaluation and Testing - IMUET}

IMUET is the acronym for integrated method for usability evaluation and testing, another topic currently under development by the author's research group. It must be pointed out that this is not a DfX, because it does not suggest the generation of a product easy to evaluate or test from the usability point of view. Instead, starting from the description of an industrial product, the IMUET generates a homogeneous collection of methods to measure its usability [16].

The IMUET is based on a collection of filters and tables that relate the several components involved in the usability evaluation and testing activities: methods, dimensions, features, principles, etc. A sophisticated mechanism of weights allows generating the result, consisting in the optimum set of dimensions and in the related methods to measure the product usability in the best way. Some hints about the application of the evaluation and testing methods integrate this result, in order to allow its application even for non-expert users.

The most interesting issues of the IMUET can be identified in a clear and effective definition of the components and of their relationships, and in the automatic generation of the integrated evaluation and testing method.

\section{Activities}

The research activities develop as follows. First, the components characterizing the DGLs-CF, the DFIU and the IMUET, are clearly identified and classified. After that, a mapping among them takes place, in trying to answer to some important questions, as: what are the corresponding components of the DFIU/IMUET in the DGLs-CF? What is the current compatibility degree? Are there missed components somewhere? Are there possible big problems? If yes, what could be the actions to solve these problems? Next, the attempt to really integrate the DFIU/IMUET in the DGLs-CF takes place, by trying to house some examples of pieces of information related to the usability issues inside the DGLs-CF data structures. Here, again, there could be some problems and the goal of this phase is exactly to highlight, characterize and classify them.

The three activities are described in the following.

\subsection{Classification of the DGLs-CF/DFIU/ IMUET Components}

The components of each method are collected and summarized in the following, followed by the description of their adoption. This will be the starting point for the next activities.

\section{DGLs-CF components}

- (Class of) product features: this component allows describing the products to be optimized using the DGLs-CF.

- (Class of) technological characteristics: here there is all the information related to the available manufacturing and verification processes and technologies.

- ISO GPS standards: inside the DGLs-CF, the formalization, the management, and the generation of knowledge, obey to the principles expressed by the ISO GPS standards. This ensures homogeneity, compatibility with other methods and tools, etc. ISO GPS standards are considered as a reference, as a guide.

- Actors: this component allows characterizing the people involved in the DGLs-CF adoption: the designers, the manufacturers, and the inspectors (verification experts). They are, as a matter of facts, the users of the DGLs-CF; moreover, the experts among them own the knowledge needed to develop the following DGLs-CF sub-components.

- Rules: rules are the description of the conditions used to check the compatibility between the product and the processes used to manufacture and verify it. Rules are generated by crossing each feature/characteristic pair.

- Compatibility expressions: the compatibility cited in the previous sentence needs to be quantified. These expressions allow generating numeric values representing how the product features answers to the process characteristics (requirements).

- Actions: these are the hints suggested by the DGLs-CF in order to maximize the compatibility between the product and the processes.

Referring to Figure 3, where some simplifications have been introduced in order to get the comprehension 
of what follows easier, the DGLs-CF works as follows. First, designers, manufacturers, and inspectors, describe the class of the available technologies, for example, the rapid prototyping technology called fused deposition modeling [17] - in terms of characteristics. After that, they do the same with the class of products - for example, car lights, in terms of features. This information allows the generation of a knowledge base containing the rules and the compatibility expressions to evaluate the compatibility between the class of the products and the classes of the available manufacturing and verification processes. After this setup phase, the DGLs-CF is configured by focusing on a specific product - for example, the headlight of a specific brand car - and on the specific brand and model of the available manufacturing and verification technologies. Thanks to all of this, the DGLs-CF can collect and manage all the information to generate some sets of actions, named redesign-reconfiguration packages, to be adopted by the actors in redesigning the product and/or reconfiguring the processes to get the best compatibility between them. All of this happens obeying to the ISO GPS principles and it is performed by seven specialized modules. Figure 3 shows some empty spaces but this is intentional. They will be filled thanks to the research described in this paper.

\section{DFIU components}

- Application domain: this component represents all the information related to the domain where the DFIU is adopted: product specifications, production technology details, etc.

- Users: the final users of the product to be designed are described here, from the points of view of per- sonal data, skill, etc. This component describes also the several ways the product is expected to be used; it contains all the elements used to generate the use case diagrams [1]

- Usability experts: this component allows characterizing the people in charge of generating the use case diagrams, etc.

- Knowledge base of analogies, metaphors, and logical methods: this collects some analogies and metaphors [18-22], together with the references to the main tools that could help their generation or finding $[23,24]$.

- Usability principles: this is the knowledge needed to design a product respecting the rules expressed in the standards ISO 9241 - Ergonomic requirements for office work with visual display terminals

- -, ISO 13407 - Human-centered design processes for interactive systems -, and ISO 20282 - Usability of everyday products.

- Selection tools: these elements are embedded in the DFIU and help the DFIU users in filtering all the concepts and solutions found in the knowledge base. Methods as the decision matrix, the go-no go evaluation, etc. [5], are involved here, borrowed again from the industrial design and engineering domain.

- Guidelines: this component constitutes the output of the DFIU. The guidelines suggest some design solutions to embed usability issues inside the industrial product since the beginning of its lifecycle.

Briefly, the DFIU adoption comes in this way. The usability experts, starting from the information about the

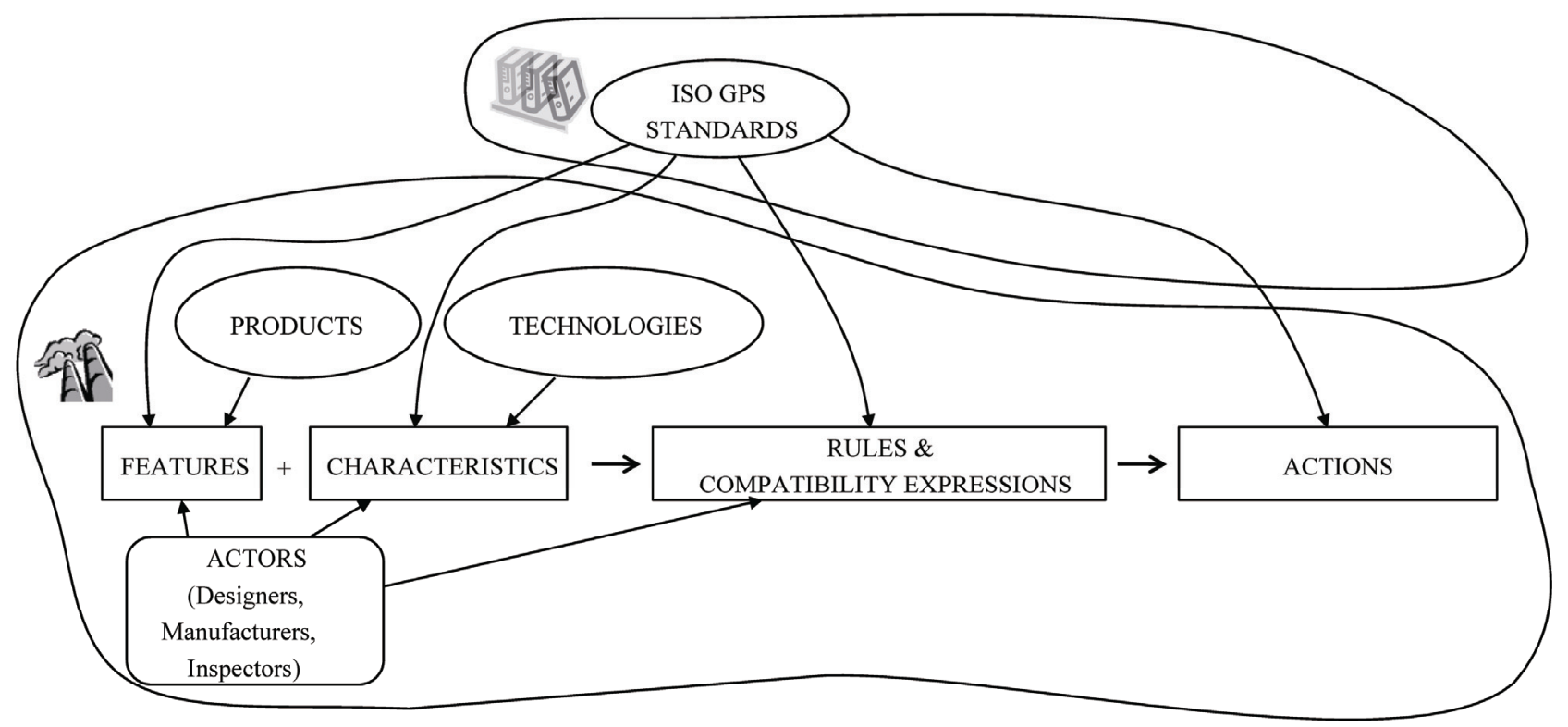

Figure 3. The graphical representation of the DGLs-CF adoption. 
application domain, the users, and the use scenarios of the product to be designed, define some use case diagrams that lead the DFIU activities. Next, the DFIU helps in finding innovative concepts by exploiting analogies, metaphors, the TRIZ method, etc. Then, all the generated and highlighted concepts are filtered, ordered, and assembled homogeneously by the selection tools, exploiting the usability principles. The result of all of this is a set of guidelines.

\section{IMUET components}

- Features: they describe the product to be evaluated and tested from the usability point of view.

- Methods: this component collects all the information related to the methods considered by the IMUET for the usability evaluation and testing. Among them, there are the pluralistic walkthrough, the consistency inspection, the shadowing method, the co-discovery learning, the coaching method, etc. [25-27].

- Usability principles: of course, here the ISO standards are exploited again, together with other principles as the Shneiderman's eight golden rules of interface design [16], the Nielsen's heuristics [1], and so on.

- Dimensions: the dimension concept is a key point for the IMUET. Dimensions allow describing the product features using a homogeneous and effective language, oriented to the usability issues. Dimensions are derived directly from the usability principles as affordance, natural mapping, feedback, etc, and their elaboration, started in [26].

- Usability inspectors: this component describes the users of the IMUET. Inspectors could be both usability experts and simple users of the method; for this reason some attention is paid on expressing the result of the IMUET elaboration in a real usable way.

- Weights: the relationships among the several components of the IMUET, expressed by tables, are driven and affected by a sophisticated system of weights, allowing a fine tuning of the method and a perfect customization of it, given the conditions of the application domain.

- Users: this component allows describing the users of the product. This information is used to set the values of the weights in the tables that represent the relationships between the components of the IMUET.

- Integrated evaluation and testing method: this is the result of the IMUET elaboration.

Regarding the adoption of these components, the IMUET starts by allowing the description of the product features. These features are set not only thanks to the information related to the product itself, but also considering the users - and this determines mainly the weights associated to the components, and the dimensions, that guarantee an uniform and effective description. After that, the IMUET exploits the knowledge regarding the usability principles and a wide set of evaluation and testing methods. Then, the dimensions are used again as the main indicator to weight quantitatively the usability of the product under evaluation and/or testing. For this reason, the dimensions drive the generation of a collection of forms to be filled by the usability inspectors during the evaluation and testing activities. The collection of these forms is the result of the IMUET elaboration, the integrated method offered to the IMUET users in a usable way, enriched with all the hints for an easy application in the field.

The considerations on how to highlight and evaluate the relationships among all these components are the subject of the next activity.

\subsection{Mapping the DGLs-CF/DFIU/IMUET Components to Each Other}

The second activity consists in linking semantically the several components of the three methods considered in this research. Table 1 shows the outcomes of this activity. The first three columns correspond to the DGLs-CF, the DFIU, and the IMUET respectively, while each row contains a specific DGLs-CF component with the related components present in the other two methods. The fourth column contains some important notes clarifying the details of this mapping.

The content of Table 1 sets and demonstrates the strong affinity among the three methods considered here. Almost all components relate to each other, except for the last two - Users -, but the note in the table clarifies that this result is as normal as expected.

\subsection{Integrate the DFIU / IMUET inside the DGLs-CF}

Table 1 represents the required condition to go further with the research. The next step is focused on the evaluation of the compatibility between the DGLs-CF data structures and the components of the two methods related to usability issues. The complex knowledge base of the DGLs-CF, consisting in twelve tables, is not reported here; it is described in detail in [14]. Nevertheless, a simple way to check the compatibility exploits the examples of all the components, as shown in Table 2. This table allows verifying that the components are semantically compatible and that they can be considered all together, homogeneously, sharing the same data structures, in a design for multi-X method. 
Table 1. Mapping the DGLs-CF/DFIU/IMUET components to each other.

\begin{tabular}{|c|c|c|c|}
\hline DGLs-CF & DFIU & IMUET & Notes \\
\hline (Class of) product features & Application domain & Features & $\begin{array}{l}\text { No problems here. Except for the need for distinguishing } \\
\text { better the several pieces of information in the application } \\
\text { domain of the DFIU }\end{array}$ \\
\hline \multirow[t]{2}{*}{$\begin{array}{l}\text { (Class of) technological charac- } \\
\text { teristics }\end{array}$} & $\begin{array}{l}\text { Knowledge base of } \\
\text { analogies, meta- } \\
\text { phors, and logical } \\
\text { methods }\end{array}$ & Methods & $\begin{array}{l}\text { Here the DFIU component is, as a matter of facts, the } \\
\text { technology used to process the product. This is why this } \\
\text { relationship takes place. The IMUET methods are consid- } \\
\text { ered like the technologies of the DGLs-CF, because they } \\
\text { are the tools to process the product }\end{array}$ \\
\hline & Usability principles & Usability principles & This mapping is straightforward \\
\hline ISO GPS standards & & Dimensions & $\begin{array}{l}\text { This mapping takes place because the dimensions are the } \\
\text { way to uniform the description language of the features } \\
\text { inside the IMUET. The ISO GPS standards have exactly } \\
\text { the same role in the DGLs-CF }\end{array}$ \\
\hline Actors & Usability experts & Usability inspectors & This mapping is straightforward \\
\hline $\begin{array}{lll}-1 & 0\end{array}$ & Selection tools & Weights & $\begin{array}{l}\text { Rules and compatibility expressions measure mutually the } \\
\text { product and the processes. The same is done by the selec- } \\
\text { tion tools and by the weights in the DFIU and in the IM- } \\
\text { UET, respectively. } \\
\text { It must be pointed out that compatibility equal to zero in } \\
\text { the DGLs-CF means that something has to be necessarily } \\
\text { done to the product, because the available manufacturing } \\
\text { and verification technologies cannot be changed. Com- } \\
\text { patibility equal to zero in the DFIU and in the IMUET is } \\
\text { not so dramatic; the considered concept is simply dis- } \\
\text { carded by the selection tool in the DFIU, and the same } \\
\text { happens for an evaluation or testing method in the } \\
\text { IMUET }\end{array}$ \\
\hline \multirow[t]{2}{*}{ Actions } & Guidelines & $\begin{array}{l}\text { Integrated evaluation } \\
\text { and testing method }\end{array}$ & $\begin{array}{l}\text { This mapping is straightforward. } \\
\text { These three items represent the same thing, an usable tool } \\
\text { to be used by the users of the methods to design a product } \\
\text { for manufacturing and verification, to design the usability } \\
\text { inside a product, and to evaluate and test the usability of } \\
\text { an existing product respectively }\end{array}$ \\
\hline & Users & Users & $\begin{array}{l}\text { These components are not present in the DGLs-CF. This } \\
\text { is normal; the DGLs-CF does not consider usability issues } \\
\text { (otherwise this research would have no sense). The next } \\
\text { step of this research will have to find a place in the } \\
\text { DGLs-CF* data structures for these components. }\end{array}$ \\
\hline
\end{tabular}

Table 2 shows again that there are not big problems in integrating the usability issues inside the DGLs-CF. All the components of the usability methods considered here are semantically compatible with the DGLs-CF ones, and for this reason they can be easily housed in the current DGLs-CF data structures.

\section{Results}

Figure 4 shows the logical structure of the DGLs-CF*, the integrated design for multi-X method that may represent a real help in managing homogeneously design, manufacturing, verification, and usability issues. This structure, together with the content of Table 1 and Table 2, represents the result of this research, because it answers to the questions about the feasibility of integrating the new DFIU and the IMUET methods inside the existing design for multi-X collaborative framework, the DGLs-CF. The scheme shown in Figure 4 is complete; nevertheless, the arrows are not present, for readability reasons. The information flow should be clear by considering the content of Table 1 and Table 2, while the differences between the 
Table 2. Examples of all the DGLs-CF/DFIU/IMUET components.

\begin{tabular}{|c|c|c|}
\hline DGLs-CF & DFIU & IMUET \\
\hline $\begin{array}{l}\text { (Class of product) features } \\
\text { Numbers of holes (if the product is a me- } \\
\text { chanical part) }\end{array}$ & $\begin{array}{l}\text { Application domain } \\
\text { Weight measurement (if the product is a per- } \\
\text { sonal training system) }\end{array}$ & $\begin{array}{l}\text { Features } \\
\text { Alert and feedback }\end{array}$ \\
\hline $\begin{array}{l}\text { (Class of technological) characteristics } \\
\text { Dimensions of the manufacturing workspace }\end{array}$ & $\begin{array}{l}\text { Knowledge base of analogies, metaphors, and } \\
\text { logical methods } \\
\text { Metaphor scope, TRIZ principles of interest }\end{array}$ & $\begin{array}{l}\text { Methods } \\
\text { Journaled session }\end{array}$ \\
\hline $\begin{array}{l}\text { ISO GPS standards } \\
\text { The features must be encoded using simple } \\
\text { geometrical entities like planes, angles, etc. }\end{array}$ & $\begin{array}{l}\text { Usability principles } \\
\text { ISO } 9142 \text {, ISO } 13407 \text {, Nielsen's principles }\end{array}$ & $\begin{array}{l}\text { Usability principles } \\
\text { Flexibility of the dialogue } \\
\text { Dimensions } \\
\text { Memorability }\end{array}$ \\
\hline $\begin{array}{l}\text { Rules } \\
\text { The maximum dimensions of the product } \\
\text { must fit the dimensions of the available } \\
\text { manufacturing technology workspace } \\
\text { Compatibility expressions } \\
\text { IF product_max_hole_depth }<\text { probe_lenght } \\
\text { THEN compatibility }=1 \\
\text { ELSE compatibility }=0\end{array}$ & $\begin{array}{l}\text { Selection tools } \\
\text { One of the criteria of the decision matrix is } \\
\text { the evaluation of the compatibility between } \\
\text { the weight measurement and the TRIZ princi- } \\
\text { ple "Universality" }\end{array}$ & $\begin{array}{l}\text { Weights } \\
\text { The compatibility between the alert and feed- } \\
\text { back and the journaled session is measured } \\
\text { using weights associated to dimensions }\end{array}$ \\
\hline $\begin{array}{l}\text { Actions } \\
\text { Split the product model }\end{array}$ & $\begin{array}{l}\text { Guidelines } \\
\text { The personal training system must explain the } \\
\text { exercises to the users aloud }\end{array}$ & $\begin{array}{l}\text { Integrated evaluation and testing method } \\
\text { The journaled session method is used to meas- } \\
\text { ure the memorability of the product interface. }\end{array}$ \\
\hline & $\begin{array}{l}\text { Users } \\
\text { The user P, a well trained athlete, determines } \\
\text { the requirements of the product to be evalu- } \\
\text { ated and tested. }\end{array}$ & $\begin{array}{l}\text { Users } \\
\text { The user Q determines the weights associated } \\
\text { to the dimensions used to evaluate and test the } \\
\text { product. }\end{array}$ \\
\hline
\end{tabular}

current situation and the starting point appears straightforward when comparing Figure 4 with Figure 2.

Even if this structure clearly refers to the DGLs-CF*, the analogies and the relationships present in it can be used as a reference in other researches and domains. The effort used here in analyzing, classifying and relating to each other the several pieces of information may be potentially exploited every time usability issues need to be considered inside a design process.

\section{Conclusions}

In this paper, we have evaluated the feasibility of integrating usability engineering issues inside a collaborative framework for industrial product design. The architecture and the knowledge management of the DGLs-CF - a design for multi-X method covering the manufacturing and the verification of the industrial product lifecycle -, have been exploited to indentify, classify, and put into relation- ship the components of two new methods: the DFIU and the IMUET, regarding the usability design and the usability evaluation and testing respectively. The positive outcomes of this evaluation allow widening the coverage of the DGLs-CF, by adding the possibility to design the usability inside the product since the beginning of its lifecycle, and to redesign poorly-usable existing products.

Now the author's research group knows for sure that the DGLs-CF*, the integrated release of the DGLs-CF, can be developed in full. This will be the future work related to this research. Next to it, the DGLs-CF* will be tested in the field and further publications will report the results of these validation activities.

\section{Acknowledgments}

The author would like to thank dr. eng. Ilaria Cristofolini $\mathrm{Ph} . \mathrm{D}$. for her invaluable contribution to the study and the development of the DGLs-CF. Moreover, thanks go to 


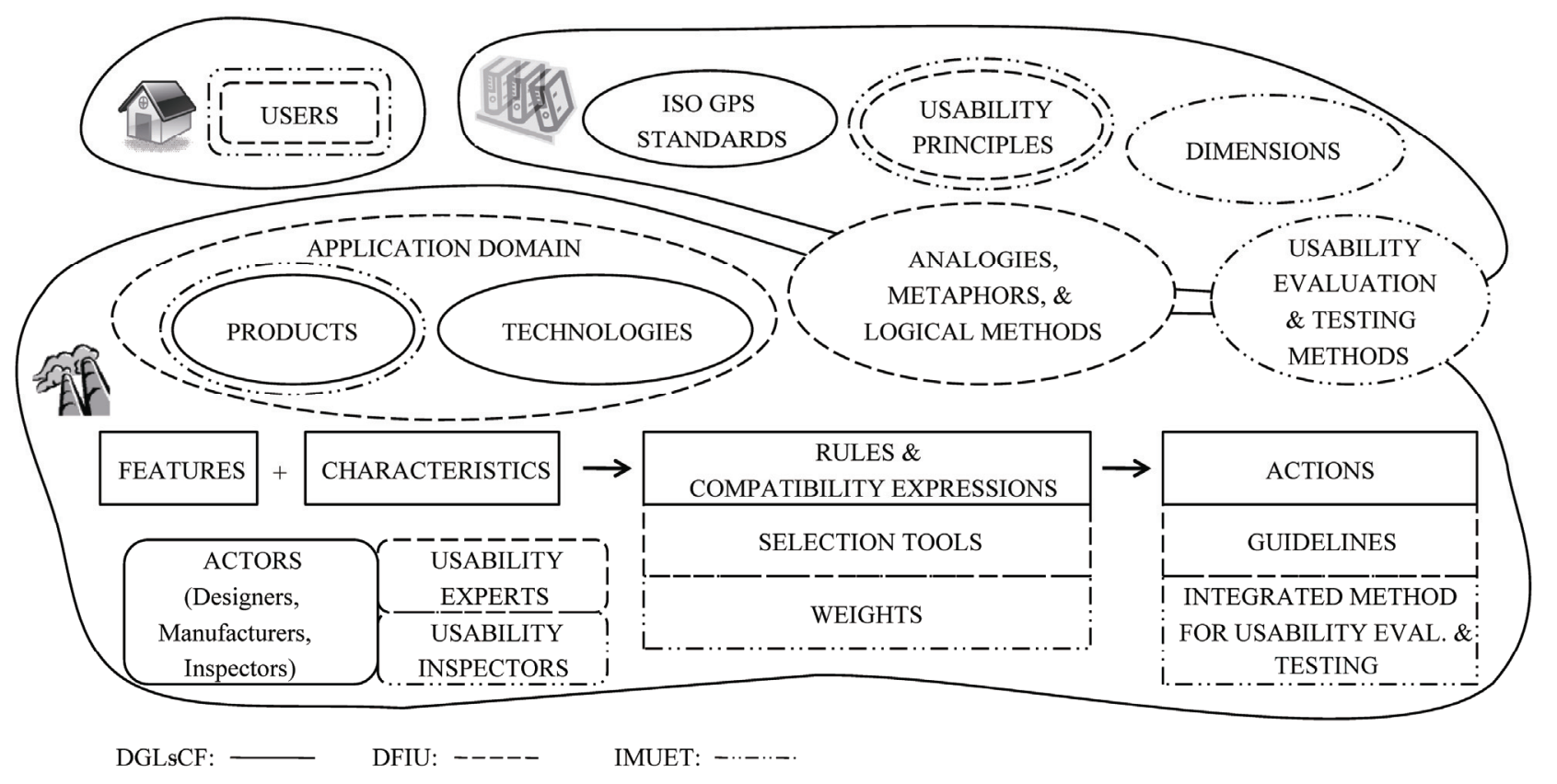

Figure 4. The logical structure of the DGLs-CF*, the result of this research.

eng. Marco Dall'Armellina and eng. Eleonora Piva, who worked on the DFIU and on the IMUET respectively.

\section{References}

[1] J. Nielsen, "Usability Engineering," Academic Press, Cambridge, MA. 1993.

[2] G. Pahl and W. Beitz, "Engineering Design: A Systematic Approach," Springer, 1995.

[3] K. T. Ulrich and S. D. Eppinger, "Product Design \& Development," Mac Graw Hill, 2000.

[4] K. Otto and K. Wood, "Product Design," Prentice Hall 2000.

[5] D. G. Ullman, "The Mechanical Design Process," McGraw-Hill, 2003.

[6] R. D. Coyne et al., "Knowledge-Based Design Systems," Addison Wesley, 1989.

[7] D. M. Andersen, "Design for Manufacturability \& Concurrent Engineering," CIM Press, Lafayette, CA, 2003.

[8] K. Lee, "Evolutionary Design and Re-Design Using Design Parameters and Goals," Journal of Engineering Design, Vol. 15, No. 2, 2004. doi:10.1080/0954482031000150170

[9] F. Noel, D. Brissaud and S. Tichkiewitch, "Integrative Design Environment to Improve Collaboration between Various Experts," Annals of the CIRP, Vol. 52, No. 1, 2003.

[10] G. Boothroyd, P. Dewhurst and W. Knight, "Product Design for Manufacture and Assembly, 2nd Edition Revised and Expanded," Marcel Dekker, New York, 2002.

[11] G. S. Altshuller, D. W. Clarke, L. Shulyak and L. Lerner,
"40 Principles: TRIZ Keys to Innovation [Extended Edition]," Technical Innovation Center, Inc., 2005.

[12] Y. S. Kim and D. S. Cochrani, "Reviewing TRIZ from the Perspective of Axiomatic Design," Journal of Eng Design, Vol. 11, No. 1, 2000, pp. 79-94. doi:10.1080/095448200261199

[13] B. El-Haik, “Axiomatic Quality: Integrating Axiomatic Design with Six-Sigma, Reliability and Quality Engineering," Wiley-Interscience, 2005.

[14] S. Filippi and I. Cristofolini, "The Design Guidelines Collaborative Framework, a Design for Multi-X Method for Product Development," Springer, 2010. doi:10.1007/978-1-84882-772-1

[15] ISO/TR 14638:1995, "Geometrical Product Specification (GPS)," Masterplan, 1995.

[16] A. Dix, J. Finlay, G. D. Abowdand and R. Beale, "Human-Computer Interaction (2nd Edition)," Prentice Hall, 1998.

[17] P. F. Jacobs, "Stereolithography \& Other Rp\&m Technologies: From Rapid Prototyping to Rapid Tooling," Society of Manufacturing Engineers, 1995.

[18] S. Ahmed and T. B. Christensen, "Use of analogies by novice and experienced design engineers," Proceedings of the ASME 2008 International Design Engineering Technical Conferences \& Computers and Information in Engineering Conference, IDETC/CIE 2008, Brooklyn, New York, 3-6 August 2008.

[19] J. S. Linsey, K. L. Wood and A. B. Markman, "Increasing Innovation: Presentation and Evaluation of the Wordtree Design-by-Analogy Method," Proceedings of the ASME 2008 International Design Engineering Technical Conferences \& Computers and Information in Engineer- 
ing Conference, IDETC/CIE 2008, 3-6 August 2008, Brooklyn, New York, 2008.

[20] E. M. W. Kolb, J. Hey, H. J. Sebastian and A. M. Agogino, "Meta4acle: Generating Compelling Metaphors for Design," Proceedings of the ASME 2008 International Design Engineering Technical Conferences \& Computers and Information in Engineering Conference, IDETC/CIE 2008, Brooklyn, New York, 3-6 August 2008.

[21] A. Agarawala and R. Balakrshnan, “Keepin' It Real: Pushing the Desktop Metaphor with Physics, Piles and the Pen," CHI 2006 Conference Proceedings, New York, 2006.

[22] J. Hurtienne and L. Blessing, "Metaphors as Tools for Intuitive Interaction with Technology," http://www. metaphorik.de, 2007.

[23] http://www.invention-machine.com/http://function.creax.c om/
[24] D. Wixon, "Evaluating usability methods: why the Current Literature Fails the Practitioner," Interaction, ACM, NewYork, Vol. 10, No. 4, 2003.

[25] S. H. Han, M. H.Yun, J. Kwahk and S. W. Hong, "Usability of Consumer Electronic Products," International Journal of Industrial Ergonomics, Elsevier, Vol. 28, No. 3, September 2001.

[26] E. Z. Opiyo and I. Horváth, "Using Hybrid Heuristic Evaluation Method to Uncover the Conceptual Design Tasks Supported by a Holographic Display Based Truly 3D Virtual Design Environment," Proceedings of the ASME 2008 International Design Engineering Technical Conferences \& Computers and Information in Engineering Conference IDETC/CIE 2008, 3-6 August 2008, New York, 2008. 